novocain into the sacral canal renders the latter part of the second stage of labour and delivery almost painless and at the same time gives good relaxation of the tissues and so prevents lacerations. It is safe in cases of toxæmia, such as eclampsia, as it has no effect upon renal or hepatic function. It lowers the blood-pressure and intracranial tension and is said not to inhibit uterine contractions. There is less risk of shock or post-partum hæmorrhage and the fotus seems to be free from any harmful influence. It is used in cases of heart disease and pulmonary tuberculosis. Some obstetricians say that novocain or stovaine injected at the dorsal level, is ideal for Cæsarean section.

It is not in extensive use as it is in surgical work, as it involves a skilled administrator. Also the effect of the injection rarely lasts for more than an hour so that it is only favourable for the last of the second stage and during delivery. In some cases it seems to have only a slight effect.

Of rectal or synergistic analgesia, as advocated by Swathmeny I have had no experience. It consists in the intramuscular administration of morphin sulphate $\frac{1}{6} \mathrm{gr}$. early in a solution of 2 c.c. of $5^{\circ}$ per cent. magnesium sulphate, followed later by a second or several injections of the magnesium alone. When labour is fully established an injection of $2 \mathrm{oz}$. of olive oil is passed into the empty rectum and this is followed by a mixture of ether $2 \frac{1}{2} \mathrm{oz}$., alcohol 2 oz., quinine hydrobromate 10 to $20 \mathrm{gr}$. in $4 \mathrm{oz}$. of olive oil. The patient gets relief from the pain. A second rectal injection of small quantities of ether, alcohol and quinine may be given four hours later, if required. The method seems to be used in some hospitals in the United States and has its advocates. It seems somewhat complicated and difficult to get the patient to retain the fluid in the rectum, even although it is passed up beyond the presenting part of the fotus.

For obstetrical operations, each obstetrician has his own choice of anæsthetics. This ڤ subject belongs perhaps to surgery as much $\frac{2}{\mathbb{D}}$ as obstetrics. The general rule is that $\stackrel{\varrho}{.}$ anæsthesia should be as light as possible so $\vec{F}$ as not to interfere with uterine contractions? and to prevent P.P.H. taking place.

In conclusion, the best analgesics for the $\frac{\bar{\sigma}}{\bar{D}}$ first stage of labour are small doses of $\mathbb{\mathbb { Q }}$ morphin or its derivatives, accompanied and later substituted by scopolamine in small $\vec{\circ}$ doses. Chloral and bromide are most useful drugs. The research already done upon the use of adaline goes to prove that it is a\& useful and safe sedative in labour. In the second stage of labour nitrous oxide with of oxygen is the best anæsthetic to use in every respect. Above all, it must be impressed upon the patient that she is not to feel $\stackrel{5}{-}$ afraid, but to leave herself entirely in the $\vec{z}$ hands of her medical attendant, who should promise-and carry out this promise-to guard her against all suffering as far ass possible within the bounds of safety herself and her child.

\section{VARIETIES OF SIMPLE AND THYROTOXIC GOITRE AND THEIR DIFFERENTIATION.}

\author{
By H. GARDINER HILL, \\ M.D., F.R.C.P.,
}

THE classification of goitre, simple and $\stackrel{\circ}{\square}$ thyrotoxic, has until recent years been aㅇㅡㅡ problem of extreme complexity. Lately N there has been a tendency to simplification of terminology. The following classification would now probably meet with more or less general acceptance. The term simple goitre includes (I) diffuse colloid goitre; (2)adeno-parenchymatous goitre; (3) lymph-? adenoid goitre; and (4) simple (fœtal) $\frac{0}{0}$ adenoma. The various forms of thyrotoxic $\frac{\vec{\Phi}}{\Phi}$ goitre, on the other hand, are now classified $\stackrel{\oplus}{\stackrel{\oplus}{\varrho}}$ 
as: (I) primary Graves' disease-that is when no enlargement of the gland existed before the onset of the disease; (2) secondary Graves' disease - when toxic symptoms arise in a patient with a pre-existing simple goitre; (3) toxic adenoma - when a true foetal adenoma gives rise to toxic symptoms.

\section{SIMPLE GOITRE.}

(I) Diffuse Colloid Goitre.-This is the simple hypertrophic goitre found in adolescents and young adults. It often develops about the time of puberty. It is characterized by uniformity of outline and is unaccompanied by constitutional symptoms. The vesicles of the gland may be of diverse shapes and sizes, distended and distorted by the accumulation of colloid within them. Evidence of antecedent epithelial hypertrophy may or may not be present. When endemic, McCarrison [ $\mathrm{I}$ ] finds that this type of goitre prevails especially in the plains, at low altitudes and at the sea coast, but it is also found sporadically. McCarrison is of the opinion that diffuse colloid goitre usually progresses with remissions for from three to five years and then regresses to barely palpable, or at least relatively small dimensions before the twenty-fifth year. Hertzler and others, on the other hand, hold different views as to the end-results of this type of goitre. These will be discussed after a consideration of the second type of simple goitre, adenoparenchymatous goitre.

(2) Adeno-parenchymatous Goitre.-This is a gland in which hyperplasia, as opposed to simple hypertrophy, is pronounced. Many new vesicles are formed and areas of more or less solid glandular tissue result. After a few years fibrosis occurs and the gland is divided up into more or less circumscribed areas, the so-called "false" adenomata. It is usually considered that this type of gland is in a state of sustained over-activity, constantly straining to satisfy the needs of the tissues for its active principles but always just falling short of doing so. Clinically it is found in older patients than the diffuse colloid type, either sporadically or in en-क demic form, in the latter case in mountainous regions. The thyroid swelling is nodular. In the later stages of the uncomplicated form there is usually well-marked hypo-c등 thyroidism.

Although McCarrison regards the diffuse $\stackrel{\Phi}{\circ}^{\overparen{ }}$ colloid goitre and the adeno-parenchymatous variety as entirely separate entities, others, $\overrightarrow{0}$ and notably Hertzler [2], do not consider that this sharp distinction is warranted. Hertzler is of the opinion that the adeno-8 parenchymatous goitre is only a later stage 3 of the diffuse colloid gland. He points out or that in the early stage of simple goitre the swelling is dependent on a uniform increase of colloid in the acini throughout the gland. Subsequent increase in the size of the gland $\bar{z}$ is due both to increase in the amount of colloid, hypertrophy of the acinal epithelium 3 and the development of new acini. Thesece later changes he considers are gradual and permanent, and with the continued develowment of the accessory acini the gland be comes irregular and nodular, i.e., the adenoparenchymatous type.

(3) Lymph-adenoid Goitre.-The existence $\overrightarrow{\vec{D}}$ of this type of goitre has been recently de- 3 monstrated in human beings by Williamson and Pearse [3]. They define it as the hyper-trophic reaction of a physiologically insuffi- 3 cient organ, but one in which undue strain has fallen upon the "lymphogenic" function: of the gland. It will be remembered that these authors consider that the normalo thyroid has two functions: (I) the production of secretion proper, lymphogenic secretion, containing no thyroxin-this is the result of activity of the reticulo-endothelial cells in the thyroid with the production of lym-N phocytes in the inter-follicular lymph-spaces :0 (2) the accumulation of colloid, whicho contains the thyroxin moiety of the thyroidळ products. In lymph-adenoid goitre the $e^{+}$ characteristic feature is an over-production ${ }_{0}^{-}$

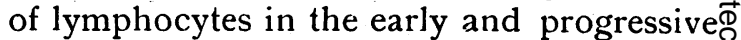
stages of the disease, followed later by 
fibrosis and atrophy. This is the gland of myxœedema. McCarrison [4] has produced lymph-adenoid goitre in rats by dietetic deficiency. He suggests that the deficiency is chiefly one of the vitamins $A, B$, and $C$. His experimental rats developed the condition in spite of adequate ingestion of iodine. As the goitre in his animals corresponded exactly to the lymph-adenoid goitre described by Williamson and Pearse in man, he considers it unlikely that the latter is due to iodine deficiency either. As Williamson and Pearse point out, the picture in lymphadenoid goitre in man is a typical one, because a once much enlarged thyroid tends finally to shrink into a small knot of fibrous tissue unrecognizable as a thyroid gland except for its position.

(4) Fetal Adenoma.-This is a tumour of the thyroid and the only true adenoma. Fœtal adenomata are isolated nodules completely surrounded by or resting upon the substance of the thyroid gland. They are independent of it in structure and growth and consequently in clinical features. They are frequently seen in small children when they are no larger than a hazel nut. They are always round or ovoid, usually solitary. They grow independently of the thyroid, slowly but persistently. They are free from the periodic progressions and regressions so common in general involvement of the thyroid gland. They grow gradually and with age either degenerate into cysts or they may become mildly toxic or malignant.

\section{ThyRotoXic GoITRES.}

The term thyrotoxic goitre is now generally considered to include three main syndromes, primary Graves' disease, secondary Graves' disease and toxic adenoma, the latter term only being applied to true foetal adenomata, the circumscribed and independent tumours which in some cases become toxic. The latter is. a comparatively infrequent occurrence when the numerous cases of thyrotoxic goitre of the other two types are considered,
(I) Primary Graves' disease is the typical syndrome in which all the well-known symptoms, ocular, cutaneous, circulatory, nervous and gastro-intestinal, of exoph thalmic goitre are present and in which thyrotoxic symptoms and goitre develop듬 together. Williamson and Pearse [5] state $\overline{\bar{c}}$ that the thyroid changes are those of an $\bar{\varnothing}$ "adenoid" goitre in roo per cent. of theseos cases. The basal metabolism is raised to a $\vec{\circ}$ level 50 to 75 per cent. above the normal, and the disease, untreated, runs a course $\overrightarrow{\mathscr{\omega}}$ lasting a number of years, characterized by응 periods of improvement and relapse, the 3 . latter generally due to intercurrent infections or mental stress. This is the typical condi- + tion of primary Graves' disease in young $\&$ women. There. is, however, a slightly? different clinical picture in primary Graves' $\overrightarrow{3}$ disease in later life, the symptoms being less characteristic and approaching those of $\stackrel{\circ}{\overrightarrow{ }}$ secondary Graves' disease. The thyroid $\overrightarrow{0}$ swelling is usually firmer and less noticeablo but thyrotoxic symptoms are severe: Williamson and Pearse have pointed out that in these cases there is a primaryo arterio-capillary sclerosis of the gland which $\frac{\varnothing}{\circ}$ is usually part of a general arterio-capillary $\overrightarrow{\vec{O}}$ fibrosis.

(2) In secondary Graves' disease, on the other hand, thyrotoxic symptoms develop in a simple goitre which has been in exist- $\frac{3}{3}$ ence for some years. In these cases the eye signs are usually less prominent and the cardiac disturbance relatively more marked. The preceding simple goitre may be either one of the simple hypertrophic (diffuse colloid goitre) or the simple hyperplastic and nodular (adeno-parenchymatous) types. N In these glands, after some years, fibrotic changes occur and thyrotoxic symptoms are liable to supervene. Secondary Graves' disease, developing in the nodular type of adeno-parenchymatous gland, has been re- $\overleftarrow{\Phi}$ ferred to by Plummer [6] as "toxic adenoma." It is now generally accepted that this termin- $\frac{0}{0}$ ology should not be adopted for these cases, $\underset{\mathbb{D}}{\mathbb{D}}$ a distinction being drawn between true fotal $\stackrel{\circ}{\circ}$ 
adenomata and the nodulations of a longstanding adeno-parenchymatous gland. Secondary Graves' disease is rarely seen except in women over 40, in whom one of these types of simple goitre has been present for at least fifteen years. When thyrotoxic symptoms develop the condition is usually steadily progressive and is not characterized by the periods of improvement and relapse so characteristic of the primary form. The basal metabolic rate steadily rises over a period of years and the main brunt of the thyrotoxæmia falls on the cardiovascular system, resulting frequently in cardiac dilatation and auricular fibrillation.

\section{DifFEREnTIAL Diagnosis.}

The clinical differentiation of the first two varieties of simple goitre, the diffuse colloid and the adeno-parenchymatous, is often a matter of considerable difficulty. The essential differences, namely, a uniform homogeneous enlargement in the former, and an irregular nodular swelling in the latter, may not be so well-marked as this clear-cut classification would suggest. The uniform colloid goitre of one observer may appear nodular to another; moreover, what appears to be a uniform gland at clinical examination may turn out to be a nodular gland at operation. Generally speaking, the history is usually shorter in the diffuse colloid type, which is especially found in its early stages as an accompaniment of such physiological events as puberty and pregnancy. The adeno-parenchymatous gland, if thyrotoxæmia has not already supervened, is usually accompanied by symptoms of hypothyroidism in the later stages. The recognition of the third type, lymph-adenoid goitre, depends on the finding of a hard atrophic thyroid in association with myxœdema. As Williamson and Pearse point out, this is the "woody" thyroid of Riedel's disease, socalled "chronic inflammatory thyroiditis." The fourth type, the true fœtal adenoma, is not likely to cause much difficulty in diagnosis. The nodules are usually isolated, round or ovoid, often solitary and freely movable. A more important diagnostic problem than the recognition of the individual types of simple goitre is the diagnosis of early thyrotoxæmia. In the primary form of Graves' disease this is not likely to cause much difficulty if it is remembered how frequently this condition develops as a result of shock, mental stress or infection at times of physiological stress such as puberty, pregnancy, the puerperium and climacteric. The onset of thyrotoxæmia in 3 an existing goitre, secondary Graves' disease, or is, however, often more difficult to diagnose, the onset of symptoms being more gradual and the usually accepted cardinal signs of the fully-developed form being rarely seen. In both types it is important to remember the great value of a history of loss of weight for which no other cause can be found, This is an almost invariable accompaniment of thyrotoxæmia and depends on the rise i basal metabolic rate which is a characteristi feature of both types of the disease. Other signs of great value are a persistently elevated $\triangle$ pulse-rate and some degree of vascularity in $\overrightarrow{\vec{O}}$ the thyroid, as evidenced by pulsation and 3 a systolic bruit heard when a stethoscope is applied over the gland. Finally, it is worth recording that many clinicians attach con- 3 siderable importance to Bram's [7] test as a simple clinical indication of thyrotoxicity. This test depends on the fact that the subjects of thyrotoxæmia show an unusual degree of tolerance to quinine hydrobromide, while most other individuals, and notably을 those with simple goitre, do not. The latter N develop symptoms of cinchonism after very few doses of this drug, while the former can tolerate fifteen, thirty, or more grains a day as long as the thyrotoxæmia persists. It is noteworthy that the increased tolerance to quinine hydrobromide shown by thyro.? toxic cases gradually diminishes as the condition improves. 


\section{REFERENCES.}

I. MCCARrison, R. "The Simple Goitres," London, I928.

2. Hertzler, A. E. "Diseases of the Thyroid Gland," London, 1929.

3. Williamson, G. S., and Pearse, I. H. Brit. Med. Journ., i, 1929, 4.

4. MCCARRISON, R. Brit. Med. Journ., i, 1929, 5.

5. Williamson, G. S., and Pearse, I. H. Journ. Pa!h. and Bact, Edinburgh, 1925, xxviii, 361.

6. Plummer, H. S. Journ. Amer. Med. Assoc., Chicago, I92 I, Ix Xvii, 243.

7. BRAM, I. "Goitre: Non-surgical Types and Treatment," New York, 1924.

\section{SOME ELECTROCARDIO- GRAPHIC PROBLEMS.}

\author{
By JENNER HOSKIN, \\ M.D., M.R.C.P.
}

Physician in charge of Cardiographic Department, Royal Free Hospital, Hon. Cardiologist, St. Paul's Hospital for Genito-Urinary Diseases.

THE electrocardiograph is now considered to be an important accessory in the investigation of cardiovascular conditions. As to the interpretation of the various waves of the electrocardiogram, our knowledge has gradually increased, so that we are now able to give an accurate opinion on many problems of cardio-analysis whose diagnosis formerly could only be surmised on clinical grounds.

The scientific researches of Sir Thomas Lewis in this field have done more than anything else to place our knowledge on a surer foundation. From the American side the work of men such as Pardee and Willius has done much to correlate laboratory findings with the clinical picture.

Nowadays, most of the salient features of the electrocardiogram record can be interpreted easily, but I am of the opinion that the majority of workers are inclined to dissociate the clinical from the electrocardiographic findings, and it is with the object of bridging this gap that I am writing this paper.

Mitral stenosis causes increased work on the left auricle, resulting in hypertrophy of the muscle. This is shown by enlargement of the $P$ wave. As the degree of stenosis increases there is often asynchronism of the contraction of the auricles. This is shown electrocardiographically by a bifid or flat topped $\mathrm{P}$ wave, whose amplitude is smaller than it was prior to the occurrence of asynchronism.

In a well-developed mitral stenosis with regular rhythm, a small $P$ wave suggests auricular fatigue and foreshadows the occurrence of auricular fibrillation.

Mitral stenosis also causes increased work on the pulmonary circuit and on the right heart. The electrocardiogram, therefore, will tend to show a right-sided preponderance. If the preponderance is absent or left-sided we may expect to find one of the following associated conditions :-

(I) Mitral regurgitation.

(2) Aortic regurgitation.

(3) Adherent pericardium.

(4) Hyperpiesia.

Mitral regurgitation causes enlargement of the left ventricle and increased work ow the right heart. If the lesion is well compensated there will be relatively more hypertrophy than dilatation of the muscle, $\overrightarrow{\vec{B}}$ and the electrocardiogram will show a left- $\frac{3}{3}$ sided preponderance. In time, as compensation gets less, dilatation of the left ventricle will increase at the expense of its hypertrophy. The effect on the right ventricle will also become more marked, and this will result in hypertrophy of that chamber. 'The preponderance will now be right-sided.

Aortic regurgitation causes enlargement of the left ventricle. Until the late stages hypertrophy is relatively greater than the dilatation; one would expect therefore a left-sided preponderance. If preponderance is absent or right-sided the condition cannot be a simple case of aortic regurgitation. One of the following associated conditions must be looked for :-

(I) Mitral stenosis.

(2) Double mitral lesion with right heart load. 